\title{
Dental trauma education intervention as a positive influence among undergraduate students
}

\author{
Juliana Yuri Nagata ${ }^{1}$, Vanessa Lima de Andrade Góis ${ }^{1}$, Eliseu Aldright Münchow ${ }^{2}$, \\ Maria Tereza Pedrosa Albuquerque ${ }^{3}$
}

Correspondence: Dr. Juliana Yuri Nagata

Email: ju_nagat@hotmail.com

\begin{abstract}
'Department of Dentistry, Federal University of Sergipe, São José, Lagarto - SE, Brazil, ${ }^{2}$ Department of Dentistry, Federal University of Governador Valadares, Minas Gerais, Brazil, ${ }^{3}$ Department of Clinical Dentistry, Federal University of Bahia, Salvador, BA, Brazil
\end{abstract}

\section{ABSTRACT}

Objective: To investigate the effect of dental trauma educational intervention among undergraduate students of a Federal University in Brazil. Materials and Methods: Students $(n=125)$ enrolled in the dentistry $(n=70)$, nursing $(n=33)$, and speech therapy $(n=22)$ courses were invited to attend a dental trauma lecture and also to answer a questionnaire about their confidence in managing crown fracture and tooth avulsion, before (T0) and immediately after (T1) the lecture. McNemar's test $(P<0.05)$ with logistic regression compared the answers between the courses. Results: Female gender $(78.4 \%)$ aged from 18 to 22 years (73.6\%) predominated among all the participants. Dentistry students scored higher correct answers $(54.3 \%)$ in T0 when compared to nursing (12\%) and speech therapy $(9 \%)$ students, concerning the storage medium for tooth fragment transportation. Likewise, few dentistry students (22.9\%) and no nursing and speech therapy students knew about the ideal storage medium for an avulsed tooth when immediate replantation was unviable. After educational intervention, a significant improvement was found between T0 and T1 $(P<0.001)$ for all courses, mainly regarding tooth avulsion with almost $100 \%$ of correct answers. Furthermore, logistic regression demonstrated that dentistry students had three times more knowledge absorption than nursing and speech therapy ones. Conclusions: The educational intervention demonstrated a significant positive impact regarding the knowledge of dental trauma emergency management among health students. Accordingly, it is essential to spread this information among health professionals to save teeth, especially in cases of avulsion.

Key words: Crown fracture, dental trauma, lecture, questionnaire, tooth avulsion, undergraduate students

\section{INTRODUCTION}

During the last decade, dental trauma has been reported to occur in an expressive part of the population around the world $(4.5 \%-17.5 \%)$, even interfering in their quality of life..$^{[1-3]}$ Among the types of dental trauma that can affect the population throughout their daily practice, especially during sports activities at schools and universities, the most common and severe

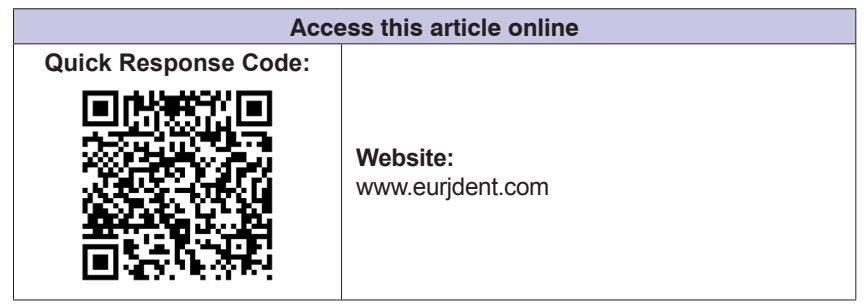

types consist of tooth fractures $(34.5 \%-62.2 \%)$ and tooth avulsion $(9 \%-11.7 \%)$, respectively. ${ }^{[4,5]}$ In these circumstances, it is well known that higher success prognosis rate has been closely related to the correct management of the traumatized tooth in the local of the incident, immediately after the dental trauma. ${ }^{[6]}$ However, most of the population in direct contact

This is an open access journal, and articles are distributed under the terms of the Creative Commons Attribution-NonCommercial-ShareAlike 4.0 License, which allows others to remix, tweak, and build upon the work non-commercially, as long as appropriate credit is given and the new creations are licensed under the identical terms.

For reprints contact: reprints@medknow.com

How to cite this article: Nagata JY, Andrade Góis VL, Münchow EA, Pedrosa Albuquerque MT. Dental trauma education intervention as a positive influence among undergraduate students. Eur J Dent 2018;12:502-7.

DOI: 10.4103/ejd.ejd_148_18 
with these accidents cannot accurately perform the correct emergency conduct for these cases, including health professionals. ${ }^{[7,8]}$

Taking this into consideration, it is essential that different communities, including educational and health professionals, should be prepared and well informed to render the appropriate conduct front a dental trauma situation. Nevertheless, studies have shown the lack of information and knowhow in dental trauma emergency care of teachers, athletes, rescue staff, paramedics, educators, sportive coaches, physicians, nurses, and dental professionals. ${ }^{[9,10]}$ These findings characterize an alarming situation that might lead to irreversible damages to the affected tooth that did not receive the appropriate treatment in the local of the accident. ${ }^{[7-10]}$ In addition, health professionals might be frequently requested to help in accidents involving tooth injury, so they might know the emergency procedures to save traumatized teeth preventing posttraumatic complications. Thinking in this way, it is important to start teaching dental trauma emergency protocols to undergraduate health students so that they can be prepared to act when this situation happens. ${ }^{[11,12]}$

It is also worth to mention that unlike dental caries and periodontal disease, which may be directly prevented, dental trauma incidents may not be predicted. Therefore, educational programs aiming to develop the population knowledge regarding the correct conduct in cases of dental trauma emergency may be the initial pathways to prevent its complications. ${ }^{[13-15]}$ In Brazil, several studies in different parts of the country (e.g., Minas Gerais, Paraíba, Pernambuco, Santa Cantarina) have demonstrated high occurrence of traumatic dental injuries among children; however, no study in the State of Sergipe has focused its attention to the knowledge of some future health professionals, mainly considering the high prevalence $(40.5 \%)$ of dental trauma in Sergipe. ${ }^{[16-19]}$ Hence, this study investigated the effect of educational intervention among undergraduate students, from three health courses, of a Federal University in Brazil, including lecture presentation and question-and-answer sessions, to promote awareness regarding emergency measures concerning tooth avulsion and tooth crown fractures.

\section{MATERIALS AND METHODS}

The present study was approved by the research ethics committee at a Federal University in Brazil.
Educational intervention lecture regarding dental trauma emergency management was carried out in a Federal University in Brazil to a total of 125 undergraduate students of three health courses: dentistry $(n=70)$, nursing $(n=33)$, and speech therapy $(n=22)$. All the participants signed written consent form and all of them maintained their right to withdraw from the study at any time. Besides the lecture, the assessment was performed using a dual-part questionnaire: The first part contained the participants' demographic information and the second part was related to the awareness, knowledge, and attitude toward dental trauma emergency protocol for tooth crown fractures and tooth avulsion. In this second part, particular focus was presented on storage medium transportation for crown fractures fragments and tooth avulsion [Table 1]. Briefly, the questionnaire application was divided in three phases: pretest (T0), intervention, and posttest (T1). The pretest and posttest were carried out through the application of the mentioned questionnaire which was taken immediately before and after the lecture. This informative lecture was presented in Portuguese language during $40 \mathrm{~min}$ by one of the authors, regarding general concepts of dental trauma and how to deal in an emergency situation of crown fracture and avulsion injuries. A computer, a projector, and a screen were used to perform the lecture. The presentation was finished with a question-and-answer discussion and an audience to discuss the remaining doubts of the participants. The results were tabulated and a McNemar's test with logistic regression was used to compare the responses between the graduation courses before and after the intervention, with the significance level set at $5 \%(P<0.05)$.

\section{RESULTS}

The demographic data indicated that most of the participants $(56 \%, n=70)$ were dental school students (nursing, $n=33,26.4 \%$; speech therapy, $n=22,17.6 \%)$ aging from 18 to 22 years $(74 \%)$ and belonged to the female gender $(78.4 \%)$. Table 2 demonstrates the information related to the answers obtained before and after the intervention lecture (Part II of the questionnaire). Regarding the storage selection to transport tooth crown fragment, $78 \%$ of the students recognized, before the intervention lecture (T0), the importance of carrying it to a dentist; however, only $35.2 \%$ would transport the fragment correctly, and $36.8 \%$ believed that dry storage selection was the most appropriated transportation 


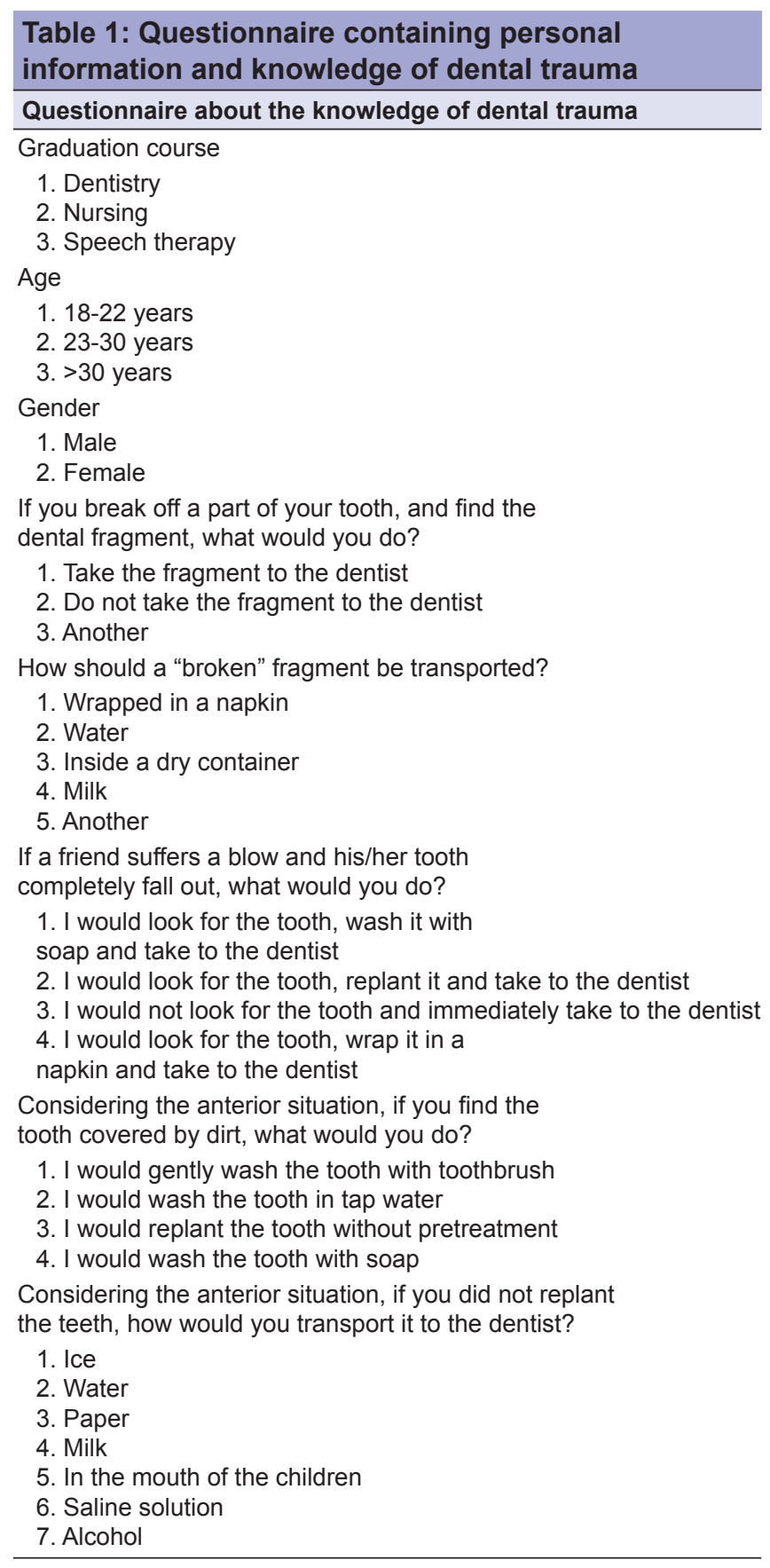

form in this case [Table 2 and Figure 1]. Pondering each course separately, dentistry students showed higher percentage $(54.3 \%)$ of correct answers before the lecture (T0) when compared to nursing $(12 \%)$ and speech therapy students $(9 \%)$, concerning storage medium for tooth fragment transportation [Table 3]. After educational lecture, a significant improvement of knowledge was observed from baseline (T0) to postlecture evaluation $(\mathrm{T} 1)(P<0.001)$ with almost all the participants understating the importance of carrying the fractured tooth to dentist $(97.6 \%)$ in water $(75.2 \%)$ [Table 3 and Figure 1 ].

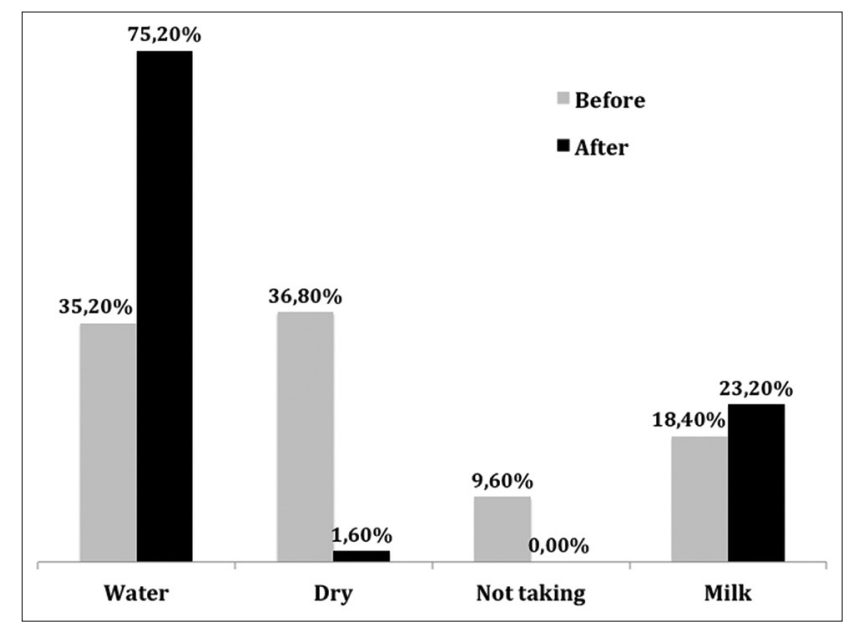

Figure 1: Crown fracture fragment transportation answers before (T0) and after (T1) lecture

Regarding tooth avulsion, it was observed that before the lecture, the participants showed unsatisfactory awareness (24\%) concerning the correct conduct in cases of tooth avulsion, which should be replanted in the moment of the trauma [Table 2]. However, the big majority $(84 \%)$ recognized that a dirty avulsed tooth should be carefully washed and managed before the replantation [Table 2]. Proceeding on this track, before the lecture, only $13 \%$ of all the participants affirmed that they would store an avulsed tooth in milk; however, after the lecture, almost all the students $(98 \%)$ were able to identify the correct storage media to transport avulsed teeth [Figure 2]. Describing apart each course, it was possible to see that before the lecture, few dentistry $(22.9 \%)$ and no nursing and speech therapy students knew about the ideal storage medium (milk) for avulsed tooth transportation when immediate replantation was unviable. After educational intervention, a significant improvement was found between the baseline (T0) and postlecture evaluation (T1) $(P<0.001)$, for all the evaluated courses, with almost $100 \%$ of correct answers [Table 3].

Furthermore, logistic regression after the lecture demonstrated that dentistry students presented 3.28 times more capability of knowledge absorption when compared to nursing and speech therapy ones. In addition, nursing and speech therapy students showed $63 \%$ and $71 \%$ less knowledge about fracture first-aid knowledge than dentistry students, respectively.

\section{DISCUSSION}

Dental trauma represents an accidental episode usually associated with undesirable effects (e.g., crown 
Nagata, et al.: Educational intervention on undergraduate students

\begin{tabular}{|c|c|c|c|c|}
\hline \multirow[t]{2}{*}{ Questions } & \multicolumn{2}{|c|}{ T0 (\%) } & \multicolumn{2}{|c|}{ T1 (\%) } \\
\hline & Correct & Incorrect & Correct & Incorrect \\
\hline Carry fractured crown fragment to dentist & $100(78)$ & $25(22)$ & $124(97.6)$ & $124(97.6)$ \\
\hline Storage medium for fractured fragment & $44(35.2)$ & $56(64.8)$ & $73(75.2)$ & $73(75.2)$ \\
\hline Immediate replantation of avulsed tooth & $26(20.4)$ & $74(79.6)$ & $115(90.5)$ & $115(90.5)$ \\
\hline Management of messy avulsed tooth & $107(84)$ & $18(16)$ & $127(100)$ & $127(100)$ \\
\hline Storage medium for avulsed tooth & $16(13)$ & $109(87)$ & $127(100)$ & $127(100)$ \\
\hline
\end{tabular}

Table 3: Descriptive analysis of the answers according to the courses before and after the dental trauma lecture

\begin{tabular}{|c|c|c|c|c|c|c|c|c|c|}
\hline \multirow[t]{2}{*}{ Knowledge } & \multicolumn{3}{|c|}{ Dentistry $(n=70)$} & \multicolumn{3}{|c|}{ Nursing $(n=33)$} & \multicolumn{3}{|c|}{ Speech therapy $(n=22)$} \\
\hline & T0, $n(\%)$ & $\mathrm{T} 1, n(\%)$ & $P^{*}$ & T0, $n(\%)$ & $\mathrm{T} 1, \boldsymbol{n}(\%)$ & $P^{*}$ & T0, $n(\%)$ & $\mathrm{T} 1, n(\%)$ & $P^{*}$ \\
\hline Crown fracture & $38(54.3)$ & $49(70.0)$ & 0.0009 & $4(12.1)$ & $22(66.7)$ & $<0.001$ & $2(9.1)$ & $22(100.0)$ & $<0.001$ \\
\hline Avulsion & $16(22.9)$ & $70(100.0)$ & $<0.001$ & $0(0.0)$ & 31 (93.9) & $<0.001$ & $0(0.0)$ & $22(100.0)$ & $<0.001$ \\
\hline
\end{tabular}

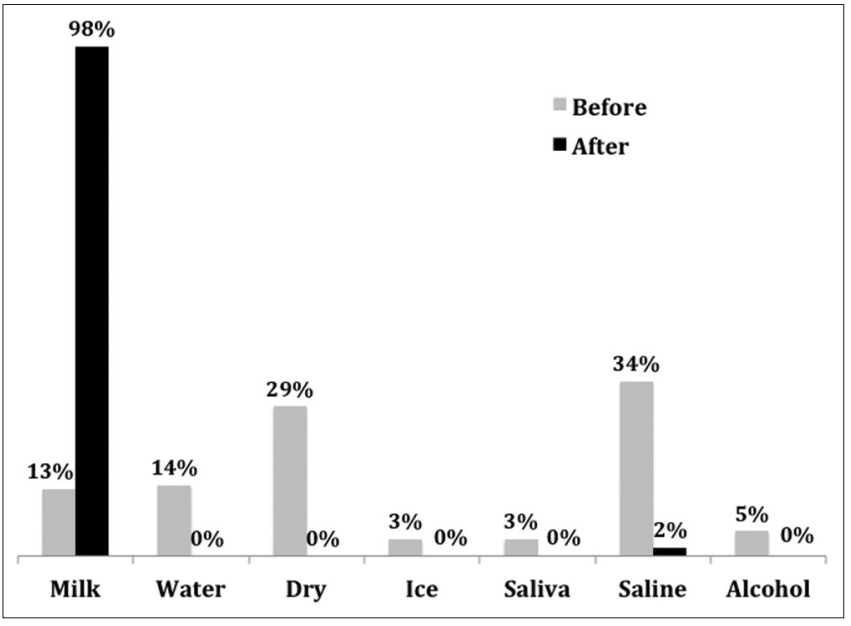

Figure 2: Tooth avulsion storage medium answers before (T0) and after (T1) the lecture

discoloration, pulp necrosis, root resorptions, and partial or complete loss of the injured teeth). ${ }^{[7,20]}$ Some of these consequences, especially the root resorption, may lead to an undesirable condition, the tooth lost. Thus, situations like this could be largely prevented by spreading information to the populace regarding the ideal management front an emergency dental trauma situation, specially tooth avulsion and fractures. Furthermore, health professionals should be aware of emergence dental trauma conduct since they might be demanded when it happens. ${ }^{[7,13-15]}$

In this scenario, preventive lectures, mainly to those communities directly connected to the most susceptible group suffering dental trauma (children), seem to be a pathway to decrease the possible damages caused by dental injuries. Facing this reality, the present study applied questionnaires before and after a dental trauma emergency lecture to compare the preliminary and afterword knowledge of the participants regarding the correct conduct to be followed in dental trauma situations to 125 undergraduate students from health courses of Lagarto, a city in the state of Sergipe, Brazil. In general, before the lecture, the participants showed lack of knowledge regarding dental trauma first-aid management, where $<50 \%$ of the undergraduate health students were able to specify the correct protocol to transport fractured crown fragment and avulsed tooth.

Concerning the transportation of a crown fractured fragment, 46 subjects (36.8\%) affirmed that the best way to carry the fragment would be under dry conditions, demonstrating lack of knowledge regarding this topic. It is important to mention that dehydration conditions may interfere in the prospect tooth adaptation and restoration. As a matter of fact, the dental trauma management guidelines, published by the International Association for Dental Traumatology (IADT) and the American Academy of Pediatric Dentistry (AAPD), advocates that the fractured fragment reattachment to the tooth is considered the first option to achieve better esthetic and functional reestablishment for the traumatized patient. ${ }^{[6]}$

Seeking this ideal treatment, it was observed, after the lecture, an expressive increase in the selection of the correct protocol (take the fragment hydrated to the dentist) by the students, attaining a correct rate of almost $100 \%$. Previous studies have demonstrated opposite results about the knowledge on crown fracture transportation with greater $(48.6 \%$ and $64.86 \%)$ confidence on managing fractured tooth with Hong 
Kong and London students, respectively. ${ }^{[11,13]}$ Besides the good hydration properties provided to the fragment by water or saline solution, the literature recently demonstrated an alternative, the egg white, which may also be suitable as a transportation medium for coronary fragments, contributing positively to the future adhesion of restorative material during dental attachment. ${ }^{[21]}$

The design of this study also focused on the knowledge of tooth avulsion management, and unfortunately, this aspect still remains unknown among most of the participants since only $20.4 \%$ recognized the importance of replantation of an avulsed tooth before the lecture. This finding corroborates with a previous study, which showed that only 3\% of sports and medical university students have been instructed about replantation. ${ }^{[2]}$ Moreover, when replantation is impracticable, IADT and AAPD recommend to store the avulsed tooth in milk; ${ }^{[23]}$ however, most of the students $(33.60 \%)$ believed that the saline solution could be the ideal storage medium for tooth transportation before the lecture. These results suggests the lack of knowledge concerning saline solution detrimental effects on periodontal ligament cells, which does not afford good osmolality features for their survival, a mandatory factor for better prognosis of the replantation, preventing ankylosis and root resorption. ${ }^{[2]}$ This assumption was similar to international scenario that has examined dentistry undergraduate students from all over the world, encountering that only $26.9 \%, 22.3 \%$, and $20 \%$ of Saudi Arabian, Hong Kong, and Japanese undergraduate students, respectively, have known the proper method to transport an avulsed tooth. ${ }^{[12,13,25]}$ Although the baseline scores (T0) were low, after the lecture (T1), the correct conduct increased to $90.5 \%$, demonstrating positive feedback from the students after the intervention lecture.

To our knowledge, scarce investigations have evaluated the acquaintance of dental trauma management among undergraduate students from general health courses, so the present study decided to include nursing and speech therapy students, which constantly works with urgency situations and oral cavity conditions, respectively. ${ }^{[7,22]}$ Based on the results presented in this study, it became clear the critical necessity to disseminate knowledge regarding dental trauma first-aid management in the university community. Forthcoming, students awareness regarding dental trauma should not be limited only to lectures but must also be spread throughout the technology apps and educational methods based on problem-based learning, to effectively prevent dental trauma complications.

\section{CONCLUSIONS}

Within the limitations of this study, it is reasonable to conclude that most of the undergraduate students did not present previous awareness about first-aid management of crown fracture and tooth avulsion. However, the dental trauma educational intervention disclosed a positive impact in the knowledge acquisition regarding the emergency conducts mainly in cases of tooth avulsion. Hence, educational programs should be developed for college students in the health area to encourage them to correctly conduct an emergency dental trauma episode.

\section{Acknowledgments}

We thank Dr. M. S. Salas for her expert assistance with the statistics analysis (Federal University of Governador Valadares).

\section{Financial support and sponsorship}

Nil.

\section{Conflicts of interest}

There are no conflicts of interest.

\section{REFERENCES}

1. Lam R. Epidemiology and outcomes of traumatic dental injuries: A review of the literature. Aust Dent J 2016;61 Suppl 1:4-20.

2. Azami-Aghdash S, Ebadifard Azar F, Pournaghi Azar F, Rezapour A, Moradi-Joo M, Moosavi A, et al. Prevalence, etiology, and types of dental trauma in children and adolescents: Systematic review and meta-analysis. Med J Islam Repub Iran 2015;29:234.

3. Schuch HS, Goettems ML, Correa MB, Torriani DD, Demarco FF. Prevalence and treatment demand after traumatic dental injury in South Brazilian schoolchildren. Dent Traumatol 2013;29:297-302.

4. Ugolini A, Parodi GB, Casali C, Silvestrini-Biavati A, Giacinti F. Work-related traumatic dental injuries: Prevalence, characteristics and risk factors. Dent Traumatol 2018;34:36-40.

5. Azodo CC, Agbor MA. Prevalence and unmet treatment need of traumatized incisor among Cameroonian schoolchildren in North West province. Odontostomatol Trop 2015;38:33-8.

6. Diangelis AJ, Andreasen JO, Ebeleseder KA, Kenny DJ, Trope M, Sigurdsson A, et al. International association of dental traumatology guidelines for the management of traumatic dental injuries: 1 . Fractures and luxations of permanent teeth. Dent Traumatol 2012;28:2-12.

7. Iyer SS, Panigrahi A, Sharma S. Knowledge and awareness of first aid of avulsed tooth among physicians and nurses of hospital emergency department. J Pharm Bioallied Sci 2017;9:94-8.

8. Awad MA, AlHammadi E, Malalla M, Maklai Z, Tariq A, Al-Ali B, et al. Assessment of elementary school teachers' level of knowledge and attitude regarding traumatic dental injuries in the United Arab emirates. Int J Dent 2017;2017:1025324.

9. Ravikumar D, Jeevanandan G, Subramanian EM. Evaluation of knowledge among general dentists in treatment of traumatic injuries in primary teeth: A cross-sectional questionnaire study. Eur J Dent 2017;11:232-7. 
10. Jain A, Kulkarni P, Kumar S, Jain M. Knowledge and attitude of parents towards avulsed permanent tooth of their children and its emergency management in Bhopal city. J Clin Diagn Res 2017;11:ZC40-4.

11. AlZoubi F, Mannocci F, Newton T, Manoharan A, Djemal S. What do dental students know about trauma? Dent Traumatol 2015;31:482-6.

12. Fujita Y, Shiono Y, Maki K. Knowledge of emergency management of avulsed tooth among Japanese dental students. BMC Oral Health 2014;14:34.

13. Young C, Wong KY, Cheung LK. Effectiveness of educational poster on knowledge of emergency management of dental trauma - Part 2: Cluster randomised controlled trial for secondary school students. PLoS One 2014;9:e101972.

14. McIntyre JD, Lee JY, Trope M, Vann WF Jr. Effectiveness of dental trauma education for elementary school staff. Dent Traumatol 2008;24:146-50.

15. Raoof M, Shokouhinejad N, Izadi A, Nourzadeh M, Afkham A, Forghani FR, et al. Long-term effect of an educational intervention regarding dental trauma first aid: A phase II study. Dent Traumatol 2014;30:296-301

16. Oliveira CM, Santos JS, Brasileiro BF, Santos TS. Epidemiologia dos traumatismos buco-maxilo-faciais por agressões em Aracaju/SE. Rev Cir Traumatol Buco Maxilofac 2008;8:57-68.

17. Granville-Garcia AF, Vieira IT, Siqueira MJ, de Menezes VA, Cavalcanti AL. Traumatic dental injuries and associated factors among Brazilian preschool children aged 1-5 years. Acta Odontol Latinoam
2010;23:47-52.

18. Gonçalves BM, Dias LF, Pereira CD, Filho MX, Konrath AC, Bolan MD, et al. Impact of dental trauma and esthetic impairment on the quality of life of preschool children. Rev Paul Pediatr 2017;35:448-55.

19. Silva-Oliveira F, Goursand D, Ferreira RC, Paiva PC, Paiva HN, Ferreira EF, et al. Traumatic dental injuries in Brazilian children and oral health-related quality of life. Dent Traumatol 2018;34:28-35.

20. Rocha Lima TF, Nagata JY, de Souza-Filho FJ, de Jesus Soares A. Post-traumatic complications of severe luxations and replanted teeth. J Contemp Dent Pract 2015;16:13-9.

21. Shirani F, Sakhaei Manesh V, Malekipour MR. Preservation of coronal tooth fragments prior to reattachment. Aust Dent J 2013;58:321-5.

22. Oleszkiewicz I, Emerich K. How to proceed in case of tooth avulsion State of student knowledge. Eur J Paediatr Dent 2015;16:103-6.

23. Andersson L, Andreasen JO, Day P, Heithersay G, Trope M, Diangelis AJ, et al. International association of dental traumatology guidelines for the management of traumatic dental injuries: 2. Avulsion of permanent teeth. Dent Traumatol 2012;28:88-96.

24. de Paula Reis MV, Moura CC, Soares PB, Leoni GB, Souza-Neto MD, Barbosa DZ, et al. Histologic and micro-computed tomographic analyses of replanted teeth stored in different kind of media. J Endod 2014;40:665-9.

25. Al-Shamiri HM, Alaizari NA, Al-Maweri SA, Tarakji B. Knowledge and attitude of dental trauma among dental students in Saudi Arabia. Eur J Dent 2015;9:518-22. 